\title{
pH Control during the Struvite Precipitation Process of Wastewaters
}

\author{
Diyan Radev1, Gergana Peeva², Valentin Nenov² \\ ${ }^{1}$ Department of Chemical Engineering, Burgas Asen Zlatarov University, Burgas, Bulgaria \\ ${ }^{2}$ Department of Water Treatment, Burgas Asen Zlatarov University, Burgas, Bulgaria \\ Email: peeva.gergana@abv.bg
}

Received 29 September 2015; accepted 24 November 2015; published 27 November 2015

Copyright (C) 2015 by authors and Scientific Research Publishing Inc.

This work is licensed under the Creative Commons Attribution International License (CC BY). http://creativecommons.org/licenses/by/4.0/

cc) (i) Open Access

\begin{abstract}
The high concentration of phosphorus and nitrogen in wastewater and sludge could be lowered to a certain level by struvite $\left(\mathrm{MgNH}_{4} \mathrm{PO}_{4} \cdot 6 \mathrm{H}_{2} \mathrm{O}\right)$ crystallization. One of the main factors for struvite formation is the solution $\mathrm{pH}$. It can be adjusted by non-reagent carbon $\left(\mathrm{CO}_{2}\right)$ dioxide stripping through the process of aeration. The intensity of the mass transfer between the air and the supernatant of dewatering sludge obtained from wastewater treatment plant is characterized by the volumetric liquid-side mass transfer coefficient, which can be estimated theoretically. It is found that the rate of $\mathrm{pH}$ increase depends strongly on the sparging area of the air distribution system while the air flow rate does not influence considerably the Dissolved Oxygen (D0) level which governs the $\mathrm{CO}_{2}$ stripping process. The theoretical calculated values of the volumetric mass transfer coefficient have been compared with those obtained experimentally. Based on the data obtained, relationships of $\mathrm{pH} / k_{L} a$ (mass transfer coefficient) were developed. These correlations serve as a tool for prediction of $\mathrm{pH}$ during the struvite precipitation process.
\end{abstract}

\section{Keywords}

Wastewater Treatment, pH, Carbon Dioxide Stripping, Mass Transfer

\section{Introduction}

Nitrogen and phosphorus are beneficial nutrients to many ecosystems in small amounts. In excessive, however, they cause a type of pollution called eutrophication (process causing reduction of oxygen concentration in water bodies due to significant growth of algae). The wastewaters are characterized by a high level of ammonia and phosphorus contents [1], therefore the effluents must be treated before discharging into water bodies [2] [3]. Conventional nitrogen removal from wastewater is carried out by biological nitrification and denitrification [4], or 
other methods as ion exchange [5], microwave irradiation [6] and struvite precipitation [7]. Phosphorus can be removed from wastewaters by incorporation of phosphate into Total suspended solids (TSS) and the subsequent removal from these solids. Alternative method for $\mathrm{P}$ and $\mathrm{N}$ recovery is struvite precipitation. The product could be used as a slow release fertilizer [8] [9]. This is the reason why struvite precipitation is to be widely investigated. Struvite $\left(\mathrm{MgNH}_{4} \mathrm{PO}_{4} \cdot 6 \mathrm{H}_{2} \mathrm{O}\right.$, magnesium ammonium phosphate hexahydrate-MAP) usually precipitates as a white orthorhombic crystals in a molar ratio $\mathrm{Mg}: \mathrm{MH}_{4}: \mathrm{PO}_{4}=1: 1: 1$. MAP precipitation is a function of $\mathrm{pH}$ and molar ratios among ammonia, magnesium ions and phosphorus [10]. The solubility of the product can be defined by Ksp (solubility product constant), and struvite formation occurs when the concentration product exceeds struvite's solubility product (supersaturation). The constant can be described by following equation [11]:

$$
\mathrm{Ksp}=\left[\mathrm{Mg}^{2+}\right]\left[\mathrm{NH}_{4}^{+}\right]\left[\mathrm{PO}_{4}^{3-}\right]
$$

Controlled MAP precipitation has been reported in treatment of digested sludge as source of phosphorus and ammonia. $\mathrm{pH}$ is a crucial variable that needs to be controlled in order to maximize the product production. Many authors have reported that the range of $\mathrm{pH}$ for MAP precipitation is from 8 to 11 [12]. According to the diagram showing concentration of species depending on $\mathrm{pH}$ (Figure 1), the optimal value of $\mathrm{pH}$ is about 9.6 [13].

Chemically $\mathrm{pH}$ can be controlled by using alkaline solutions as sodium hydroxide. High phosphorus and ammonia removal level were achieved at increased $\mathrm{pH}$ [14] [15]. $\mathrm{NaOH}$ is generally used for $\mathrm{pH}$ adjustment, but its addition rapidly increases $\mathrm{pH}$ value. Also the addition of $\mathrm{NaOH}$ will sharply increase the saturations of other magnesium precipitations, i.e. bobierrite and magnesite [16]. Alternative of addition of $\mathrm{NaOH}$ is the $\mathrm{CO}_{2}$ stripping process. Willams (1999) has used $\mathrm{CO}_{2}$ stripping for $\mathrm{pH}$ elevation [17]. Advantage is that $\mathrm{pH}$ increases slowly, which gives the optimum conditions for struvite crystal growth and crystallization process [18]. $\mathrm{CO}_{2}$ stripping is non-reagent process for increasing of $\mathrm{pH}$ by dissolved carbon dioxide release using aeration of liquid [19]. It is a technique where dissolved $\mathrm{CO}_{2}$ produced from an aerobic digestion process is removed from wastewater resulting in reduction of the total carbonate carbon concentration. The high concentration of $\mathrm{CO}_{2}$ in wastewater is due to the relatively low specific exchange rates which do not allow the removal of substantial quantities of $\mathrm{CO}_{2}$. Therefore, an effective $\mathrm{CO}_{2}$ control requires aeration for stripping process. When atmospheric air is placed in contact with wastewater, there is a tendency for a dissolved gas to come to equilibrium at saturation: undersaturated gas such as oxygen is transferred from the air to the wastewater, and supersaturated gas such as $\mathrm{CO}_{2}$ is transferred to the air [20].

The gas-liquid equilibrium influences the transfer of $\mathrm{CO}_{2}$ between air and wastewater. The carbonate species, $\mathrm{H}_{2} \mathrm{CO}_{3}, \mathrm{HCO}_{3}^{-}$, and $\mathrm{CO}_{3}^{2-}$, are involved in instantaneous equilibrium among each other, as shown in Figure 1. In summary, dissolved $\mathrm{CO}_{2}$ exists in the wastewater as part of the carbonate acid-base system. Therefore, the concentration of total dissolved $\mathrm{CO}_{2}$ can be altered by change of the total amount of carbonate carbon in the solution. The intensity of this process is characterized by the volumetric liquid-side mass transfer

$\log [$ species $]$ - pH Diagram

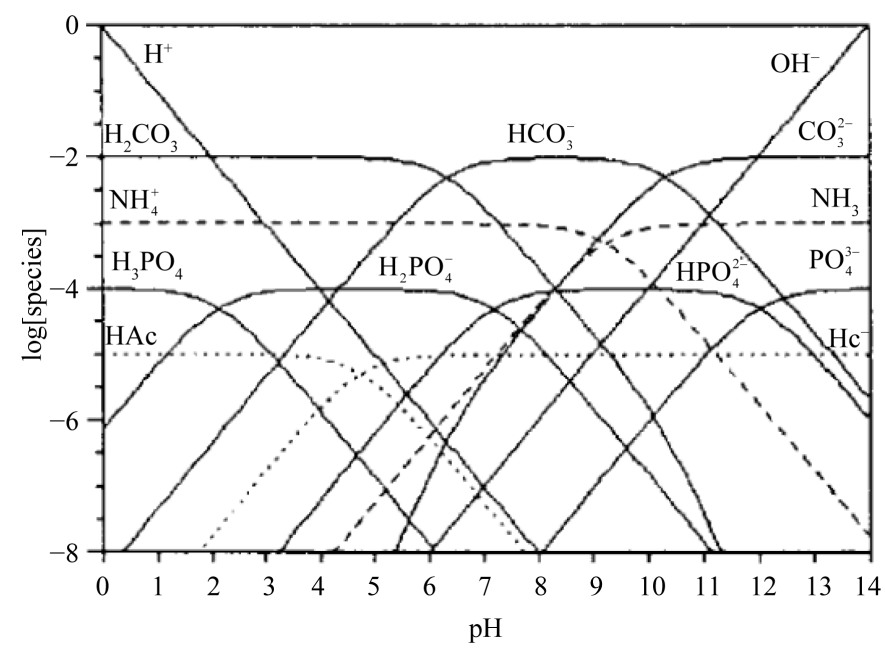

Figure 1. Concentration of species with $\mathrm{pH}$. 
coefficient, $k_{L} a$. If we estimate the volumetric liquid-side mass transfer coefficient, then we can predict $\mathrm{pH}$ solution by the following equation [21]:

$$
r_{T}= \pm k_{L} \cdot a\left(\alpha_{o L} \cdot C_{T L}-\alpha_{o L . E q} \cdot C_{T L . E q}\right)
$$

where $r_{T}, C_{T L}, C_{T L . E q}, \alpha_{0 L}$ and $\alpha_{0 L . E q}$ are the $\mathrm{CO}_{2}$ transfer reaction rate, total carbonates concentration in the liquid phase, equilibrium concentration of total carbonates in the liquid phase, $\mathrm{H}_{2} \mathrm{CO}_{3}$ fraction of the total carbonates in the liquid phase and equilibrium concentration of $\mathrm{H}_{2} \mathrm{CO}_{3}$ fraction of the total carbonates in the liquid phase, respectively.

In gas-liquid reactors, mass transfer from the gas phase to the liquid phase is a key parameter of the process. The $k_{L} a$ value in gas-liquid contacting equipment has mostly been determined by the oxygen physical absorption or desorption technique (classical method). In the actual large-scale aeration system, the application of the existing method for $k_{L} a$ determination can be limited by various factors such as absorption rate from air, complicated operating conditions, measuring equipment quality and cost, and also operator skills. Therefore, a simple theoretical way to predict the volumetric liquid-side mass transfer coefficient would be appreciated. These values can be predicted theoretically if we know how to estimate the liquid-side mass transfer coefficient $k_{L}$ and the specific interfacial area, separately [22]-[25]. In order to improve the accuracy of the theoretical model for calculating the volumetric mass transfer coefficient for $\mathrm{pH}$ adjustment using air stripping, experimental data were needed for comparison.

\section{Materials and Methods}

The digested sludge was taken from one of the digesters of wastewater treatment plant (WWTP) (Pomorie, Bulgaria). The sludge contains $9310 \mathrm{mg} \mathrm{P}_{4}-\mathrm{P} / \mathrm{kg}$ solids and dry matter of $26 \mathrm{~g} / \mathrm{l}$ as TSS. Principle scheme of WWTP-Pomorie and sampling point (digested sludge after digester) is shown in Figure 2. $\mathrm{Al}_{2}\left(\mathrm{SO}_{4}\right)_{3}$ is dosed before aeration tank.

The sludge was centrifuged in lab scale and the obtained supernatant was aerated in an up-flow reactor aiming $\mathrm{pH}$ elevation. Analytical measurement for chemical oxygen demand (COD, $\mathrm{mgO}_{2} / \mathrm{L}$ ), $\mathrm{NH}_{4}-\mathrm{N}\left(\mathrm{mg} / \mathrm{L}\right.$ ) and $\mathrm{PO}_{4}$ (mg/L) were determined by Spectrophotometer (HACH LANGE DR 3900) using cuvette test (Cuvette test-

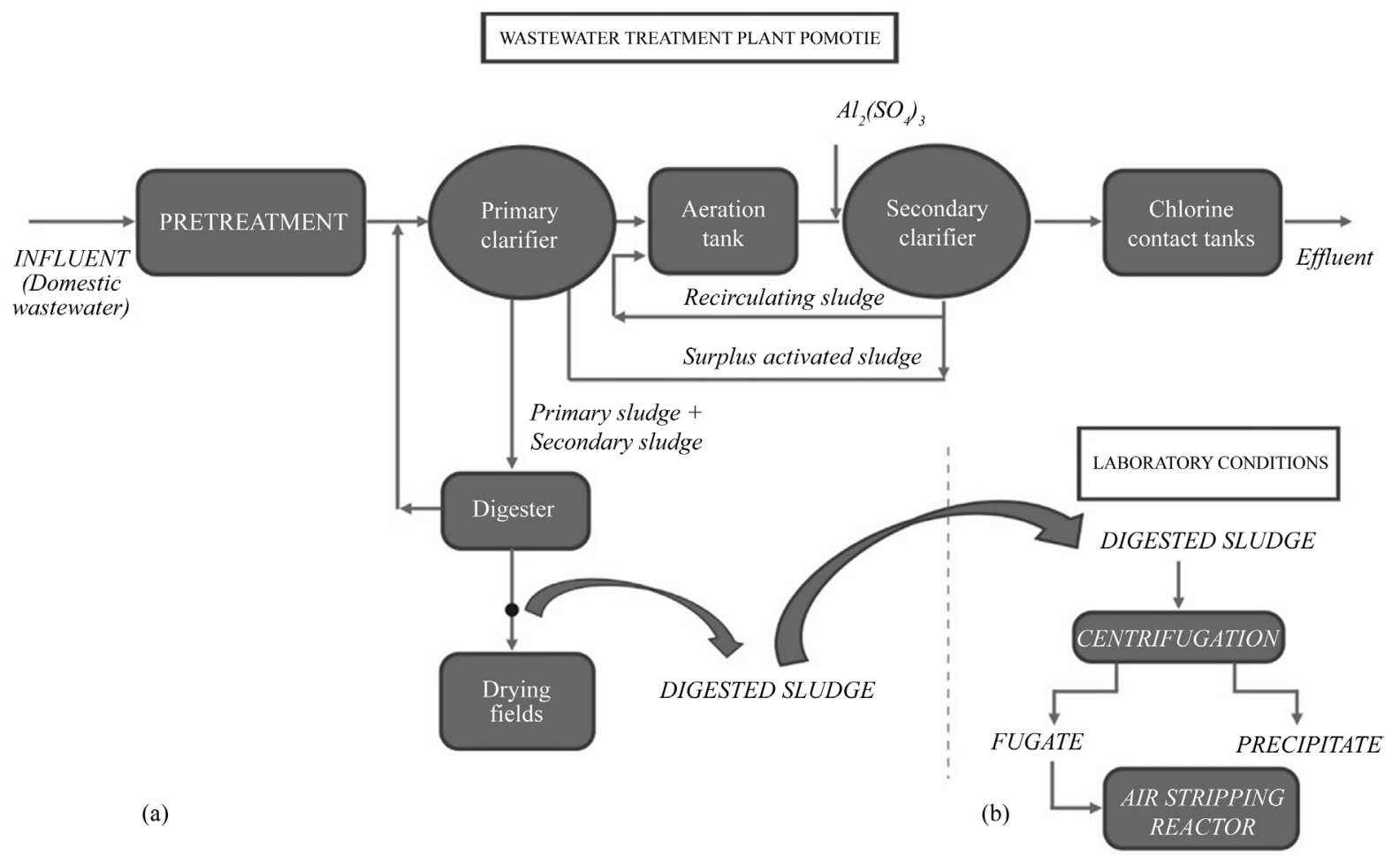

Figure 2. (a) Scheme of WWTP Pomorie and sampling point of digested sludge; (b) Sludge treatment in lab scale. 
range 5 - $90 \mathrm{mg} / \mathrm{L} \mathrm{PO}_{4}$; range 100 - $2000 \mathrm{mgO}_{2} / \mathrm{L} \mathrm{COD}$; range 2.5 - $60 \mathrm{mg} / \mathrm{L} \mathrm{NH}_{4}-\mathrm{N}$ ) and the obtained data is listed in Table 1. The samples were tested for magnesium and calcium content by the Ethylenediaminetetraacetic acid (EDTA) complexometric method [26]. The preliminary obtained information related to the concentrations of ammonia and phosphorous $\left(\mathrm{o}-\mathrm{PO}_{4}\right)$ shows that the liquid phase following the dewatering of sludge from conventional WWTP contains significant concentration of these constituents for MAP precipitation. The concentrations of the dissolved oxygen and solution $\mathrm{pH}$ were measured by Multi-Parameter Meter (HQ40d Portable).

Plastic cylindrical column with diameter of $0.05 \mathrm{~m}$ was used as reactor for the $\mathrm{CO}_{2}$ stripping process (Figure 3). Plastic perforated plate was installed at the bottom of the reactor and served as a gas sparger. Supernatant of $1000 \mathrm{ml}$ was placed in the reactor. Air compressor was run and air flow was passing through the plastic perforated plate and the supernatant was aerated. The first series of experiments were carried out at different air volumetric flow rates $(0.067 \mathrm{~m} / \mathrm{s} ; 0.134 \mathrm{~m} / \mathrm{s} ; 0.201 \mathrm{~m} / \mathrm{s})$ using large specific area yield by plate with number of orifices 132 and a diameter of each orifice $2 \mathrm{~mm}$. For the second series of experiments was used a plate with a single orifice and airflow rate of $0.067 \mathrm{~m} / \mathrm{s}$. Dissolved oxygen and $\mathrm{pH}$ level were measured in both sets of experiments. Dissolved oxygen and $\mathrm{pH}$ level were measured in both sets of experiments aiming determination influence of organic matter on $\mathrm{pH}$ elevation. For this purpose the supernatant was diluted 2, 3 and 4 times using distilled water and COD levels in the diluted samples were $650 \mathrm{mgO}_{2} / \mathrm{L}, 400 \mathrm{mgO}_{2} / \mathrm{L}$, and $320 \mathrm{mgO}_{2} / \mathrm{L}$, respectively. The measurement of oxygen concentration was needed for the experimental calculation of the volumetric mass transfer coefficient, $k_{L} a_{\text {exp }}$. Sodium sulfite $\left(\mathrm{Na}_{2} \mathrm{SO}_{3}\right)$ was added in order to deoxygenate the supernatant to an essentially zero concentration of dissolved oxygen. To increase the rate of the reaction copper sulfate $\left(\mathrm{CuSO}_{4}\right)$ was used as catalyst. After deoxygenation, the supernatant was aerated and the increasing concentration of the oxygen was recorded in order to calculate the mass transfer rate by the following equation:

$$
\frac{\mathrm{d} C_{L}}{\mathrm{~d} t}=k_{L} \frac{F}{V}\left(C_{S}-C_{L}\right)=k_{L} a\left(C_{s}-C_{L}\right)
$$

where: $C_{s}, C_{L}, a$ and $V$ are the saturation concentration of oxygen, concentration of oxygen in the body of the liquid, the specific interfacial area and the volume of the liquid, respectively.

$k_{L} a_{\text {exp }}$ was obtained after integration of the above equation:

Table 1. Values of ammonia $(\mathrm{mg} / \mathrm{L})$, phosphate $(\mathrm{mg} / \mathrm{L})$, COD $\left(\mathrm{mgO}_{2} / \mathrm{L}\right)$, calcium ions $(\mathrm{mg} / \mathrm{L})$ and magnesium ions $(\mathrm{mg} / \mathrm{L})$ in the supernatant.

\begin{tabular}{ccccc}
\hline Sample & $\begin{array}{c}\text { Concentration of } \\
\mathrm{PO}_{4}, \mathrm{mg} / \mathrm{L}\end{array}$ & $\begin{array}{c}\text { Concentration of } \\
\mathrm{NH}_{4}, \mathrm{mg} / \mathrm{L}\end{array}$ & $\begin{array}{c}\mathrm{COD}, \mathrm{mgO}_{2} / \mathrm{L} \\
\text { Concentration of } \\
\mathrm{Mg}^{2+}, \mathrm{mg}^{\mathrm{L}}\end{array}$ & $\begin{array}{c}\text { Concentration of } \\
\mathrm{Ca}{ }^{2+}, \mathrm{mg} / \mathrm{L}\end{array}$ \\
\hline Supernatant & 130 & 380 & 1260 & 102.1 \\
\hline
\end{tabular}

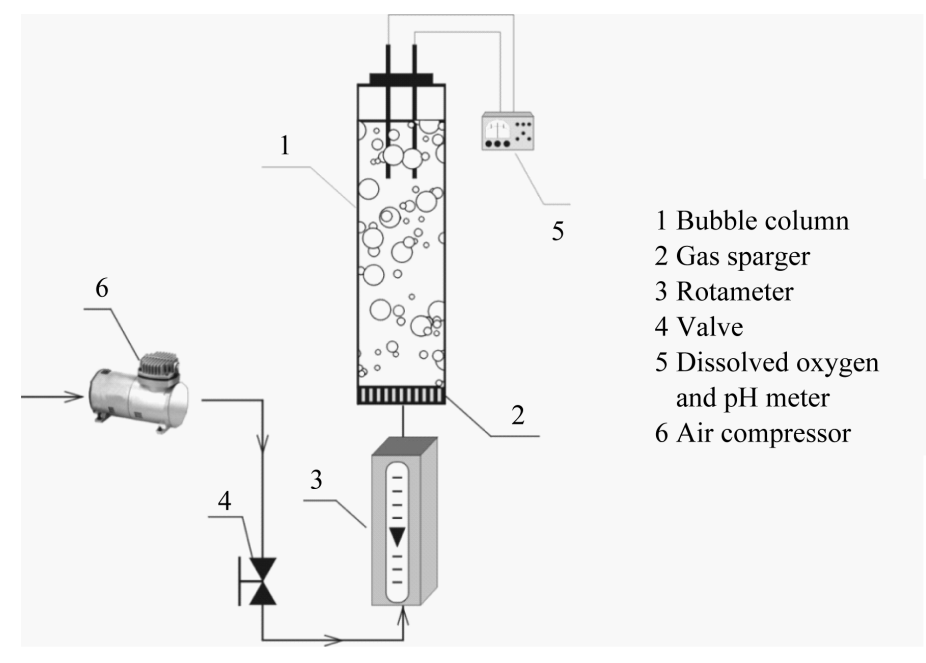

Figure 3. Experimental setup. 


$$
k_{L} a_{\exp }=\frac{1}{t} \ln \frac{\left(C_{s}-C_{L_{1}}\right)}{\left(C_{s}-C_{L_{2}}\right)}
$$

For the theoretical prediction of the volumetric liquid-side mass transfer coefficient $k_{L} \cdot a_{\text {theor }}$, we need to calculate some hydrodynamic $\left(d_{s}, f_{B}, u_{B}\right)$ and mass transfer parameters [27]-[29]. Once we have calculated the liquid-side mass transfer coefficient $k_{L}$ and the specific interfacial area $a$, some correction is needed due to the ellipsoidal shape of the bubble. Miller has introduced the following correction factor [30]:

$$
f_{c}=683 d_{s}^{1.376}
$$

The $k_{L} \cdot a_{\text {theor }}$ values should be multiplied by this correction factor for optimal prediction [31] [32]:

$$
k_{L} a_{\text {theor }}=f_{c} \sqrt{\frac{4 D_{L}}{\pi t_{c}}} \frac{N_{B} S_{B}}{\left(A H+N_{B} V_{B}\right)}
$$

\section{Results and Discussion}

\subsection{Influence of Different Air Flow Rates}

$\mathrm{pH}$ elevation and oxygen concentrations at different air flow rates were observed (Figure 4 and Figure 5). The results show evidently that within the volumetric air rate applied the effect of $\mathrm{pH}$ increase follows a similar mode

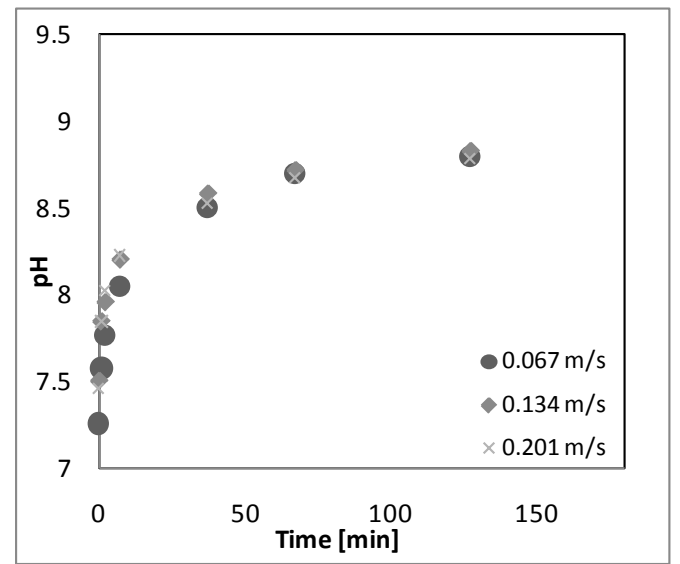

Figure 4. pH elevation by air stripping column applying different volumetric air rates.

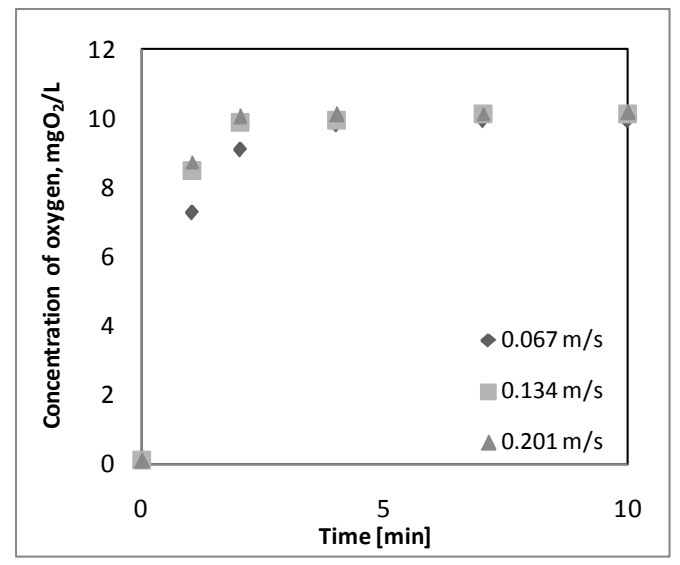

Figure 5. Concentration of oxygen apllying different volumetric air rates. 
of change. More rapidly oxygen saturation of the supernatant within the first 5 minutes of aeration was observed. $\mathrm{pH}$ increases from 7.5 to 8.4 were achieved by air stripping within 20 minutes, while $\mathrm{pH}$ values were increased up to 9 after 250 minutes of aeration. Actually, $\mathrm{pH}$ values from 8.3 to 8.5 are enough for MAP precipitation by $\mathrm{CO}_{2}$ stripping process. But many studies are showing that the optimal $\mathrm{pH}$ is in the range of 9 to 9.5 [33] [34]. The targeted $\mathrm{pH}$ of 9 was achieved after 4 hours of aeration. The slow change of $\mathrm{pH}$ after the 20th minute of aeration is an advantage of the $\mathrm{CO}_{2}$ stripping process because it restricts the rapid increase of solution saturation. As such conditions the struvite crystallization process predominates [16].

\subsection{Influence of Different Sparging Area}

Although the curves follow similar mode of change (Figure 6 and Figure 7), the rate of $\mathrm{pH}$ elevation and oxygen concentration is higher at larger developed sparging area compared to the rate of $\mathrm{pH}$ elevation and oxygen concentration using gas sparger with single orifice. When gas sparger with 1 orifice was used for aretation, $\mathrm{pH}$ was increased to 8.4 within 120 minuttes. For the same period of aeration but different gas sparger with 132 orifices $\mathrm{pH}$ achieved value of 8.8. The result is demonstrating that larger developed surface area lead in rapidly $\mathrm{pH}$ increasing because of faster oxygen saturation of solution and carbon dioxide stripping.

\subsection{Influence of Organic Contain}

The dependence of $\mathrm{pH}$ elevation on organic contain was determined (Figure 8). $\mathrm{pH}$ values of 8.7 and 9 (starting of $\mathrm{pH}=8.1$ ) were achieved within 250 minutes of aeration at $\mathrm{COD}=650 \mathrm{mgO}_{2} / \mathrm{L}, \mathrm{COD}=400 \mathrm{mgO}_{2} / \mathrm{L}$ and $\mathrm{COD}=320 \mathrm{mgO}_{2} / \mathrm{L}$, respectively. The experiment indicated that higher organic contain in the supernatant

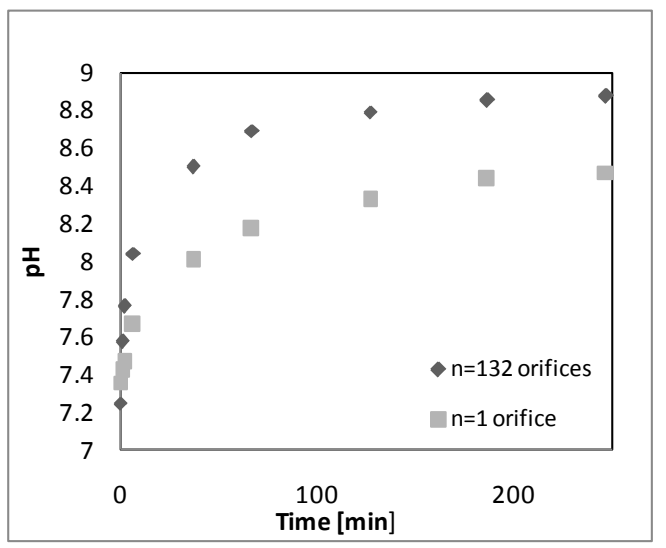

Figure 6. pH elevation applying different gas spargers.

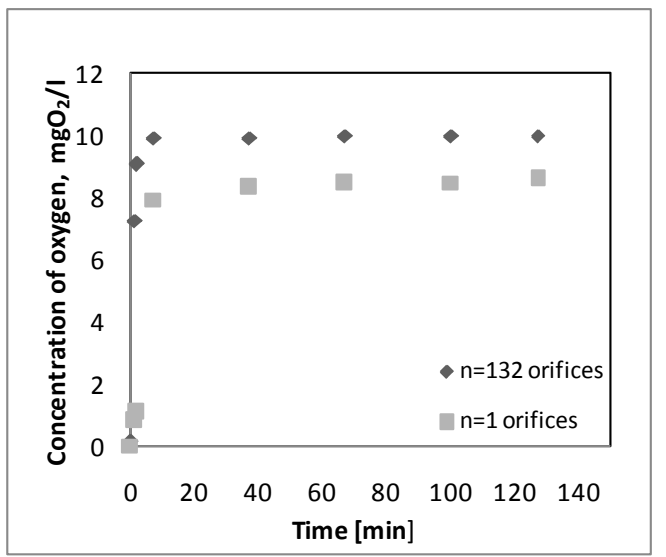

Figure 7. Concentration of oxygen applying different gas spargers. 


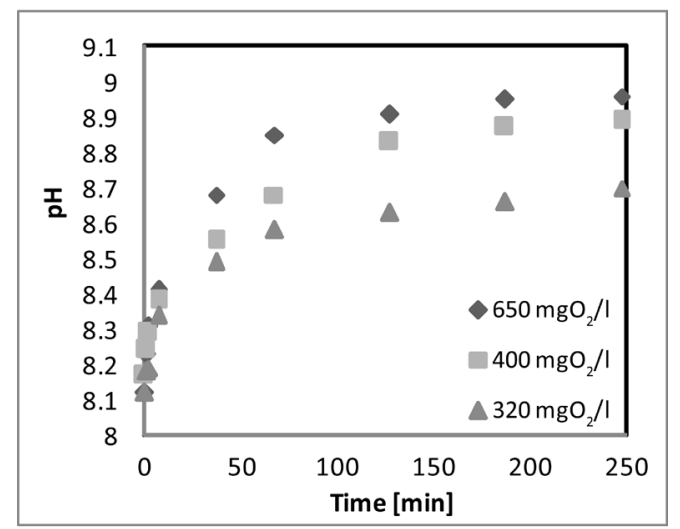

Figure 8. pH elevation applying different organic contain.

resulting in higher increase of $\mathrm{pH}$ value.

\subsection{Mass Transfer Coefficients}

The predicted of experimental data are plotted in Figure 9. The figure shows that there is relative agreement between the predicted and the experimental coefficients. The data obtained show that the experimental data are within the range of $-25 \%+25 \%$ of the theoretical trend (the central continuous line).

The theoretical and experimentally obtained mass transfer coefficients are also compared at different air volumetric rates (w, m/s) (Figure 10). These results show at higher air volumetric rates the experimental coefficients are close to the theoretical values.

Aiming to find relationships between $\mathrm{pH}, w[\mathrm{~m} / \mathrm{s}]$ and $K_{L} a\left[\mathrm{~s}^{-1}\right]$, a logarithmic function was applied. Actually, three functions were followed, namely $\mathrm{pH}=\mathrm{f}(w), K_{\mathrm{l}} a=\mathrm{f}(w)$ and $\mathrm{pH}=\mathrm{f}\left(k_{L} a\right)$ at constant time of aeration. We choose time of aeration two minutes. The $\mathrm{pH} / \mathrm{w}$ and $k_{L} a / w$ functions are presented in Figure 11. Evidently, at higher air velocity $k_{L} a$ and $\mathrm{pH}$ are increased. However, at the values of air velocity higher than $0.2 \mathrm{~m} / \mathrm{s}$ the influence of air velocity is negligible. The direct relation between $\mathrm{pH}$ and $k_{L} a$ is given in Figure 12. For the three curves shown in Figure 11 and Figure 12 the correlation coefficients over 0.98 (Figure 11 and Figure 12). Such relationships could serve as a prediction tool for $\mathrm{pH}$ in struvite precipitation reactor.

For the specific case of struvite precipitation of supernatant of digested sludge (parameters: $\left[\mathrm{PO}_{4}^{3-}\right]=130$ $\mathrm{mg} / \mathrm{L},\left[\mathrm{NH}_{4}^{+}\right]=380 \mathrm{mg} / \mathrm{L}, \mathrm{COD}=1260 \mathrm{mgO}_{2} / \mathrm{L}$ ) aerated by air flow supplied through plate (number of orifices 132 and diameter of each orifice $2 \mathrm{~mm}$ ), three logarithmic functions were elaborated:

$$
\begin{aligned}
K_{L} a & =0.0142 \cdot \ln (W)+0.0571 \\
\mathbf{p H} & =0.2431 . \ln (W)+8.4214 \\
\mathbf{p H} & =0.451 . \ln \left(K_{L} a\right)+9.5426
\end{aligned}
$$

These functions describe the interactions between the $\mathrm{pH}, \mathrm{w}(\mathrm{m} / \mathrm{s})$ and $k_{L} a$.

\section{Conclusions}

$\mathrm{CO}_{2}$ stripping was applied as an alternative method for $\mathrm{pH}$ elevation of supernatant taken from digested sludge. It was found that the rate of increase of $\mathrm{pH}$ depended strongly on the sparging area of the air distribution system while the air flow rate did not influence considerably DO level which governed the $\mathrm{CO}_{2}$ stripping process. Based on the data obtained, relationships of $\mathrm{pH} / k_{L} a$ (mass transfer coefficient) were developed. These correlations served as a tool for prediction of $\mathrm{pH}$ during the struvite precipitation process.

Relationships among $\mathrm{pH}, w[\mathrm{~m} / \mathrm{s}]$ and $K_{L} a\left[\mathrm{~s}^{-1}\right]$ were determined for the specific case of struvite precipitation using supernatant of digested sludge.

\section{Acknowledgements}

The support of the Project MIS ETC 2614, Scientific Network for Earthquakes, Landslide, and Flood hazard 


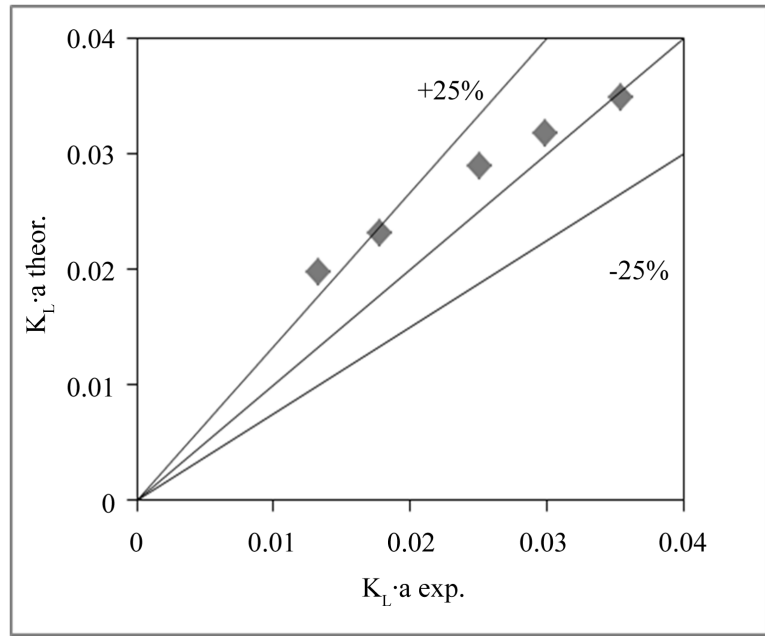

Figure 9. Comparison between the theoretical and the experimental volumetric liquid-side mass transfer coefficients $(\diamond$ : experimental data).

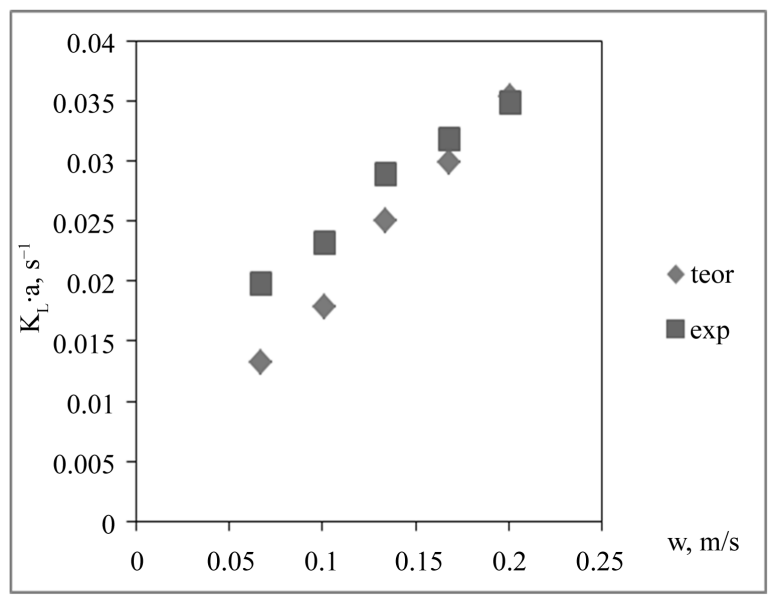

Figure 10. Volumetric liquid-side mass transfer coefficient as a function of gas velocity.

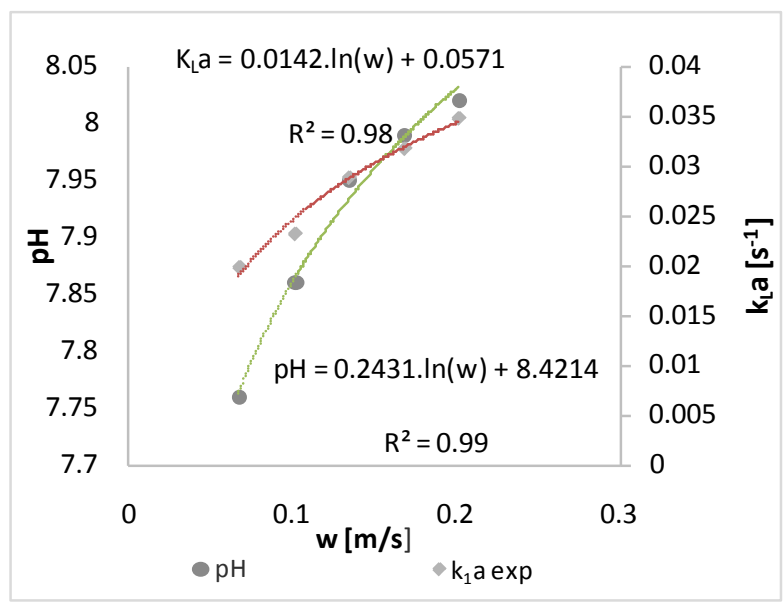

Figure 11. Relation between $\mathrm{pH}$ and $w(\mathrm{~m} / \mathrm{s})$, and $K_{\mathrm{l}} a$ and $w(\mathrm{~m} / \mathrm{s})$. 


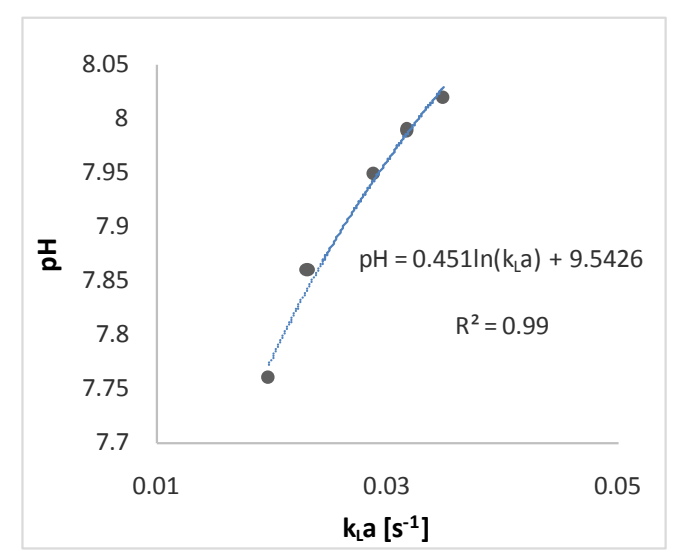

Figure 12. Relation between $\mathrm{pH}$ and $K_{l} a$.

prevention, funded under JOP “Black Sea Basin 2007-2013”.

\section{References}

[1] Deng, L.W., Zheng, P. and Chen, Z.A. (2006) Anaerobic Digestion and Post-Treatment of Swine Wastewater Using IC-SBR Process with Bypass of Raw Wastewater. Process Biochemistry, 41, 965-969. http://dx.doi.org/10.1016/j.procbio.2005.10.022

[2] Khan, F.A. and Ansari, A.A. (2005) Eutrophication: An Ecological Vision. The Botanical Review, 71, 449-482. http://dx.doi.org/10.1663/0006-8101(2005)071[0449:EAEV]2.0.CO;2

[3] Lee, S.I., Weon, S.Y., Lee, C.W. and Koopman, B. (2003) Removal of Nitrogen and Phosphate from Wastewater by Addition of Bittern. Chemosphere, 51, 265-271. http://dx.doi.org/10.1016/S0045-6535(02)00807-X

[4] Welander, U., Henrysson, T. and Welander, T. (1998) Biological Nitrogen Removal from Municipal Landfill Leachate in a Pilot Scale Suspended Carrier Biofilm Process. Water Research, 32, 1564-1570. http://dx.doi.org/10.1016/S0043-1354(97)00351-5

[5] Liu, Y.H., Kwag, J.H., Kim, J.H. and Ra, C.S. (2011) Recovery of Nitrogen and Phosphorus by Struvite Crystallization from Swine Wastewater. Desalination, 277, 364-369. http://dx.doi.org/10.1016/j.desal.2011.04.056

[6] Cho, J.H., Lee, J.E. and Ra, C.S. (2009) Microwave Irradiation as a Way to Reutilize the Recovered Struvite Slurry and to Enhance System Performance. Journal of Animal Science and Technology (Korea), 51, 337-342. http://dx.doi.org/10.5187/JAST.2009.51.4.337

[7] Rahman, M.M., Liu, Y.H., Kwag, J.H. and Ra, C.S. (2011) Recovery of Struvite from Animal Wastewater and Its Nutrient Leaching Loss in Soil. Journal of Hazardous Materials, 186, 2026-2030. http://dx.doi.org/10.1016/j.jhazmat.2010.12.103

[8] Münch, E.V. and Barr, E. (2001) Controlled Struvite Crystallisation for Removing Phosphorus from Anaerobic Digester Sidestreams. Water Research, 35, 151-159. http://dx.doi.org/10.1016/S0043-1354(00)00236-0

[9] Laridi, R., Auclair, J.C. and Benmoussa, H. (2005) Laboratory and Pilot-Scale Phosphate and Ammonium Removal by Controlled Struvite Precipitation Following Coagulation and Flocculation of Swine Wastewater. Environmental Technology, 26, 525-536. http://dx.doi.org/10.1080/09593332608618533

[10] Abbona, F. and Boistelle, R. (1979) Growth Morphology and Crystal Habit of Struvite Crystals $\left(\mathrm{MgNH}_{4} \mathrm{PO}_{4} \cdot 6 \mathrm{H}_{2} \mathrm{O}\right)$. Journal of Crystal Growth, 46, 339-354. http://dx.doi.org/10.1016/0022-0248(79)90082-4

[11] Ohlinger, K.N., Young, T.M., Schroeder, E.D. (1999) Kinetics Effects on Preferential Struvite Accumulation in Wastewater. Journal of Environmental Engineering, 125, 730-737. http://dx.doi.org/10.1061/(ASCE)0733-9372(1999)125:8(730)

[12] Hao, X.D., Wang, C.C., Lan, L. and Loosdrecht, M.C.M.V. (2008) Struvite Formation, Analytical Methods and Effects of $\mathrm{pH}$ and $\mathrm{Ca}^{2+}$. Water Science and Technology, 58, 1687-1692.

[13] El Diwani, G., El Rafie, Sh., El Ibiari, N.N. and El-Aila, H.I. (2007) Recovery of Ammonia Nitrogen from Industrial Wastewater Treatment as Struvite Slow Releasing Fertilizer. Desalination, 214, 200-214. http://dx.doi.org/10.1016/j.desal.2006.08.019

[14] Stratful, I., Scrimshaw, M. and Lester, J. (2001) Conditions Influencing the Precipitation of Magnesium Ammonium Phosphate. Water Research, 35, 4191-4199. http://dx.doi.org/10.1016/S0043-1354(01)00143-9 
[15] Battistoni, P., de Angelis, A., Pavan, P., Prisciandaro, M. and Cecchi, F. (2001) Phosphorus Removal from a Real Anaerobic Supernatant by Struvite Crystallization. Water Research, 35, 2161-2178. http://dx.doi.org/10.1016/S0043-1354(00)00498-X

[16] Zeng, L. and Li, X. (2006) Nutrient Removal from Anaerobically Digested Cattle Manure by Struvite Precipitation. Journal of Environmental Engineering and Science, 5, 285-294. http://dx.doi.org/10.1139/s05-027

[17] Williams, S. (1999) Struvite Precipitation in the Sludge Stream at Slough Wastewater Treatment Plant and Opportunities for Phosphorus Recovery. Environmental Technology, 20, 743-747. http://dx.doi.org/10.1080/09593332008616869

[18] Song, Y.H., Qiu, G.L., Yuan, P., Cui, X.Y., Peng, J.F., Zeng, P., Duan, L., Xiang, L.C. and Qian, F. (2011) Nutrients Removal and Recovery from Anaerobically Digested Swine Wastewater by Struvite Crystallization without Chemical Additions. Journal of Hazardous Materials, 190, 140-149. http://dx.doi.org/10.1016/j.jhazmat.2011.03.015

[19] Ohlinger, K.N., Young, T.M. and Schroeder, E.D. (1998) Predicting Struvite Formation in Digestion. Water Research, 32, 3607-3614. http://dx.doi.org/10.1016/S0043-1354(98)00123-7

[20] Summerfelt, S.T., Vinci, B.J. and Piedrahita, R.H. (2000) Oxygenation and Carbon Dioxide Control in Water Reuse Systems. Aquacultural Engineering, 22, 87-108. http://dx.doi.org/10.1016/S0144-8609(00)00034-0

[21] Shanableh, A. (2009) Carbon Dioxide Transfer with Chemical Equilibrium Reactions: An Alternative Mathematical Approach. American Journal of Engineering and Applied Sciences, 2, 726-734.

[22] Nedelchev, S. and Jordan, U. (2006) A New Correction Factor for Theoretical Prediction of Mass Transfer Coefficients in Bubble Columns. Journal of Chemical Engineering of Japan, 39, 1237-1242. http://dx.doi.org/10.1252/jcej.39.1237

[23] Ivanov, Zh., Stefanov, Zh. and Bogdanov, B. (2011) Gas-Side Mass Transfer Coefficient of Laboratory Column Equipped with One Sieve Tray. Proceedings: Chemical Technologies, 50, 51-55.

[24] Fan, L.S. and Tsuchiya, K. (1990) Butterworth-Heinemann Series in Chemical Engineering, Stoneham, U.S.A.

[25] Terasaka, K., Inoue, Y., Kakizaki, M. and Niwa, M. (2004) Simultaneous Measurement of 3-Dimensional Shape and Behavior of Single Bubble in Liquid Using Laser Sensors. Journal of Chemical Engineering of Japan, 37, 921-926. http://dx.doi.org/10.1252/jcej.37.921

[26] Budesinsky, B.W. (1975) A Simultaneous EDTA-Metric Determination of Calcium and Magnesium with Antipyrylazo III and Thymolphthalexon. Microchemical Journal, 20, 17-21. http://dx.doi.org/10.1016/0026-265X(75)90107-1

[27] Higbie, R. (1935) The Rate of Absorption of a Pure Gas into a Still Liquid during Short Periods of Exposure. Transactions of the AIChE, 31, 365-389.

[28] Mendelson, H.D. (1967) The Prediction of Bubble Terminal Velocities from Wave Theory. AIChE Journal, 13, 250253. http://dx.doi.org/10.1002/aic.690130213

[29] Georgiev, D. and Vlaev, S.D. (2012) Bioprocess Improvement by Design-Modified Bioreactor Flow Properties. Biotechnology \& Biotechnological Equipment, 26, 3182-3186. http://dx.doi.org/10.5504/BBEQ.2012.0031

[30] Miller, D.N. (1974) Scale-Up of Agitated Vessels Gas-Liquid Mass Transfer. AIChE Journal, 20, 445-453. http://dx.doi.org/10.1002/aic.690200303

[31] Painmanakul, P., Loubiere, K., Hebrard, G., Mietton-Peuchot, M. and Roustan, M. (1999) Dynamics of Gas-Liquid Flows in Bubble Column Reactors. Chemical Engineering Science, 54, 5237-5243. http://dx.doi.org/10.1016/S0009-2509(99)00245-6

[32] Wilkinson, P.M. and Haringa, H. (1994) Mass Transfer and Bubble Size in a Bubble Column under Pressure. Chemical Engineering Science, 49, 1417-1427. http://dx.doi.org/10.1016/0009-2509(93)E0022-5

[33] Fattah, K.P., Mavinic, D.S., Koch, F.A. and Jacob, C. (2008) Determining the Feasibility of Phosphorus Recovery as Struvite from Filter Press Centrate in a Secondary Wastewater Treatment Plant. Journal of Environmental Science and Health Part A, 43, 756-764.

[34] Uysala, A., Yilmazel, Y.D. and Demirer, G.N. (2010) The Determination of Fertilizer Quality of the Formed Struvite from Effluent of a Sewage Sludge Anaerobic Digester. Journal of Hazardous Materials, 181, 248-254.

http://dx.doi.org/10.1016/j.jhazmat.2010.05.004 